TERAKREDITASI Berdasarkan SK Dirjen Dikti Depdiknas Nomor: 65a/DIKTl/Kep/2008

MENIMBANG KOMPATIBELITAS MULTIKULTURALISME DAN ISLAM: IKHTIAR MENGGAGAS PENDIDIKAN ISLAM MULTIKULTURAL DI INDONESIA Mukhlis

ASESMEN AKHLAK MULIA: Suatu Model Alternatif Penilaian Pembelajaran Agama Siti Muri'ah

MENILAI Ulang GAGASAN NEGARA KHILÂFAH ABÛ AL-A'LÂ AL-MAUDÛDî Arsyad Sobby Kesuma

AL-A'IMMAH MIN QURAISY: ANTARA DOKTRIN DAN KEBUTUHAN SOSIAL Ahwan Mukarrom

SISTEM KALENDER ISLAM DALAM PERSPEKTIF EVOLUSI SYARI'AA Abd. Salam

Desain DakWAH untuk PEMBINAan KeAgamaAn KOMUNITAS ELIT INTELEKTUAL Bukhari 


\section{PEDOMAN TRANSLITERASI}

\begin{tabular}{|c|c|c|c|}
\hline Arab & Latin & Arab & Latin \\
\hline 1 & $=$ & = & $=\mathrm{f}$ \\
\hline ب & $=$ & ق & $=\mathrm{q}$ \\
\hline$\dot{H}$ & ts & ك & $=\mathrm{k}$ \\
\hline 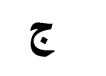 & $=$ & $J=$ & $=1$ \\
\hline$\tau$ & $=$ & b & $=\mathrm{m}$ \\
\hline$\dot{\tau}$ & $=\quad \mathbf{k h}$ & ن & $=\mathbf{n}$ \\
\hline$د$ & $=$ & و & $=\mathbf{w}$ \\
\hline$\dot{j}$ & $\mathrm{dz}$ & $\Delta$ & $=\mathbf{h}$ \\
\hline J & $=$ & $\varepsilon$ & $=$, \\
\hline j & $=$ & 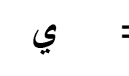 & $=\mathbf{y}$ \\
\hline س & $=$ & & \\
\hline ش ش & $\begin{array}{l}=\quad \text { sy } \\
=\quad \text { sh }\end{array}$ & \multicolumn{2}{|c|}{$\begin{array}{l}\text { Untuk Madd } \\
\text { dan Diftong }\end{array}$} \\
\hline ض & dl & $i$ & $=\hat{a}$ (a panjang) \\
\hline b & th & = & $=\hat{\mathbf{i}}(\mathbf{i}$ panjang $)$ \\
\hline ظ & $\mathbf{z h}$ & أو = & $=\hat{\mathbf{u}}$ (u panjang) \\
\hline$\varepsilon$ & $=$ & آو = & $=\mathbf{a w}$ \\
\hline$\dot{\varepsilon}$ & $=\mathbf{g h}$ & = آين & $=$ ay \\
\hline
\end{tabular}




\section{ISI}

TRANSLITERASI

ARTIKEL

Mukhlis

Menimbang Kompatibelitas

Multikulturalisme dan Islam:

Ikhtiar Menggagas Pendidikan Islam

Multikultural di Indonesia • 201-224

Siti Muri'ah

Asesmen Akhlak Mulia:

Suatu Model Alternatif Penilaian

Pembelajaran Agama • 225-248

Yusuf Hanafi

Perkawinan Anak di Bawah Umur

dalam Perspektif Hukum Islam • 249-274

Arsyad Sobby Kesuma Menilai Ulang Gagasan Negara Khilâfah

Abû al-A'lâ al-Maudûdî • 275-300

Ahwan Mukarrom Al-A'immah min Quraisy:

Antara Doktrin dan Kebutuhan

Sosial • 301-322

Abd. Salam

Sistem Kalender Islam dalam Perspektif

Evolusi Syari'ah • 323-350

Bukhari

Desain Dakwah untuk Pembinaan

Keagamaan Komunitas

Elit Intelektual • 351-370

Ahmad Munir Teologi Properti:

Telaah Eksistensi dan Fungsi

Kekayaan • 371-392

BOOK REVIEW

Ahmad Fathan Aniq Discovering Indonesian Islam through Fatâwâ • 393-408

INDEKS 


\title{
PERKAWINAN ANAK DI BAWAH UMUR \\ DALAM PERSPEKTIF HUKUM ISLAM \\ Yusuf Hanafi*
}

\begin{abstract}
Under age marriage is not a new case in Indonesia. This practice has been performed by many people either in villages or big cities for a long time. Its causes are diverse from economic factors, poor education, to superficial understanding of cultural and religious values. In addition to causing social, psychological and health problems, under age marriage brings about legal problems. For example, Syekh Puji and Ulfa's marriage opens controversy areas between traditional, Islamic, national and international laws because each has different juridical perspectives. This fact causes at least two legal problems: first, harmony between one law and another; second, challenges for marital legislation in term of under age marriage. This writing is aimed to show the urgency of marital law review to answer legislative challenges toward Islamic law harmony with globalization era today.
\end{abstract}

Keywords: Pernikahan Bawah Umur, Legislasi Undang-Undang, Harmonisasi Hukum.

KAUM muslim seringkali disudutkan oleh pertanyaan berikut, "Akankah Anda menikahkan puteri Anda yang baru berusia 6 atau 9 tahun dengan seorang lelaki tua yang telah berusia 50 tahun?" Mereka mungkin akan terdiam karena bingung atau justru marah karena tersinggung. Lalu, pertanyaan selanjutnya adalah, "Jika Anda tidak akan melakukannya, bagaimana Anda

*Penulis adalah dosen Jurusan Sastra Arab Fakultas Sastra Universitas Negeri Malang. email: sufi_rmi@yahoo.com 
bisa menyetujui pernikahan gadis ingusan berusia 6 atau 9 tahun bernama 'Â'isyah dengan Nabi Anda, Muhammad bin 'Abd alLâh?"

Nabi Muhammad saw. merupakan uswah hasanah (teladan yang baik) bagi seluruh umat Islam — di mana perilaku, tindakan, dan peri kehidupannya selalu dijadikan sebagai acuan dan rujukan. Namun sekali lagi, dalam konteks "menikahi gadis di bawah umur" ini, kaum muslim seolah dihadapkan pada pilihan yang dilematis. Sebab bagaimana pun, mayoritas muslim tidak akan pernah berpikir-apalagi melakukan tindakanmenikahkan anak perempuannya yang baru berusia 6 atau 9 tahun dengan seorang pria dewasa yang lebih pantas menjadi bapak bahkan kakeknya. Jika ada orang tua yang setuju dengan pernikahan seperti itu, kebanyakan orang, meski tidak semua, akan mencibir dan memandang sinis, terlebih kepada pria uzur yang tega menikahi bocah di bawah umur. ${ }^{1}$

Belum lama ini, umat Islam Indonesia dihebohkan oleh pemberitaan kasus pernikahan gadis di bawah umur. Pujiono Cahyo Widianto, seorang miliarder beristeri satu dan berusia 43 tahun asal Semarang yang lebih populer disapa Syekh Puji, menikahi bocah berusia 12 tahun bernama Lutviana Ulfa pada 8 Agustus 2008 lalu. Lebih heboh lagi, Syekh Puji yang juga berstatus sebagai pengasuh Ponpes Miftahul Jannah itu berencana menikahi dua gadis ingusan lain dalam waktu yang tidak terlalu lama untuk mengenapkan jumlah bilangan isteri yang dikoleksinya menjadi 4 (empat). ${ }^{2}$

Ketika berita itu merebak ke permukaan, pro-kontra pun bermunculan. Mayoritas menolaknya sekaligus menuding Syekh

'Yusuf Hanafi, "Benarkah Nabi Menikahi Gadis di Bawah Umur?", dalam http://www.islamlib.com (11 November 2008). Artikel tersebut merupakan saduran dari tulisan T.O. Shavanas, "Was Ayesha A Six-Year-Old Bridge" dalam http://www.iiie.net/node/58 (06 September 2002).

2Berita Nasional, "Syekh Puji Menikahi Bocah Berusia 12 Tahun", Suara Media, 26 Oktober 2008, 1. 
Puji mengidap phedophilia, yaitu karakter kejiwaan yang mempunyai ketertarikan seksual terhadap anak di bawah umur. Tidak ketinggalan, Majelis Ulama Indonesia (MUI) juga menfatwakan perihal keharaman tindakan Syekh Puji yang mengawini gadis ingusan di bawah umur itu. ${ }^{3}$

Syekh Puji tidak tinggal diam. Dia berdalih bahwa tindakannya itu sesuai dengan tuntunan syari'at, karena pernah dicontohkan oleh Nabi Muhammad saw. tatkala menikahi 'Â'isyah. ${ }^{4}$ Syekh Puji tidak sendiri. Pembelaan untuknya, di antaranya, datang dari Fauzan al-Anshari (dulu Kepala Departemen Data dan Informasi MMI) dan Puspo Wardoyo (pemilik Rumah Makan Wong Solo yang pernah memperoleh Poligami Award). Pembelaan serupa juga disampaikan oleh muslimah Hizbut Tahrir Indonesia (HTI) lewat juru bicaranya, Febrianti Abbasuni. ${ }^{5}$ Mereka berujar, umat Islam yang mengingkari pernikahan seperti itu berarti mengingkari sunnah Nabi, dan pada gilirannya dapat membahayakan keimanannya.

Perkawinan anak di bawah umur (child marriage — atau sering juga diistilahkan dengan early marriage), di tengah menguatnya sorotan dan ikhtiar dunia internasional untuk mereduksinya karena sederet dampak negatif dan bahaya yang ditimbulkannya, ternyata masih menjadi persoalan yang problematis dalam Islam. Seperti yang akan diuraikan dalam sub bahasan berikutnya, pandangan Islam tradisional yang dikonstruksi di atas paradigma fiqh klasik cenderung melegalkan praktik tersebut. Karena itu,

${ }^{3}$ Iin Yumiyanti, "MUI: Tak Masalah Syekh Puji Dipidanakan" dalam http://www.detiknews.com/read/ 2008/10/22/165612/1024278/10/muitak-masalah-syekh-puji-dipidanakan (22 Oktober 2008).

${ }^{4}$ Chazizah Gusnita, "Syekh Puji: Saya Punya Dasar Agama, Nggak Ngawur", dalamh ttp://www. detiknews.com / read/2008/ 10/23/ 150516/ 1024883/ 10/ syekh-puji-saya-punya-dasar-agama-nggak-ngawur (23 Oktober 2008).

${ }^{5}$ Febrianti Abbasuni, "Negara Tidak Boleh Membatasi Usia Pernikahan!", dalam http://hizbut-tahrir.or.id/2008/11/21/bolehkahnegara-membatasi-usia-minimal-pernikahan/ (21 November 2008). 
tulisan ini hadir untuk menunjukkan urgensi ijtihad baru guna menjawab tantangan legislasi menuju harmonisasi hukum Islam di era global dewasa ini.

\section{Perspektif Fiqh Klasik atas Perkawinan Anak Bawah Umur}

Allah swt. mensyari'atkan pernikahan kepada umat manusia, dan menetapkan seperangkat ketentuan untuk mengokohkan bangunannya. Di samping itu, Dia juga memperindahnya dengan ajaran-ajaran etik dan tuntunan-tuntunan moral. Allah swt. telah menjadikan utusan-Nya, Muhammad saw., sebagai uswah hasanah yang sepatutnya diteladani-di mana ia terekam dalam lembaran-lembaran sejarah menikahi gadis perawan (bikr) dan janda (tsayyib), dan juga pernah mengawini wanita muda (shaghîrah) dan tua (kabîrah). Keseluruhan isterinya itu terpilih atas pertimbangan-pertimbangan Ilahiyah yang jauh dari kalkulasi-kalkulasi fisik dan materi. ${ }^{6}$

Belakangan muncul perdebatan seputar pernikahan Nabi saw. dengan 'Â'isyah yang disebut oleh hampir seluruh literatur hadis kanonik (mudâwwanah) terjadi ketika puteri Abû Bakr itu masih "kanak-kanak". Satu kelompok menegaskan bahwa mempraktikkan pernikahan model itu berarti "menghidupkan sunnah Nabi”. Namun kelompok yang lain berpendapat bahwa kebolehan menikahi gadis yang masih di bawah umur itu merupakan hak previlige bagi Nabi saw. saja.

Sejujurnya, jika kita menengok sejarah pengundangan hukum Islam, maka kita akan menemukan fakta bahwa diskursus ini nyaris tidak terlalu intens dibicarakan (untuk tidak mengatakan “sangat minim”). Pasalnya, para fuqaha' berpandangan, tidak ada problem apapun dalam pernikahan suci tersebut. Justru yang

\footnotetext{
'Sulayman al-Qarârî, "Tazmîj al-Banât Li Tis' Sinîn bayn al-Nafy Wa alItsbât', dalam www.ahlalhdeeth. $\mathrm{com} / \mathrm{vb} /$ attachment.php?attachmentid $=60364 \& \mathrm{~d}=1224443807$.
} 
banyak mengemuka adalah kupasan dan uraian perihal keagungan dan keutamaan di balik pernikahan historis tersebut.

Yang jelas, berdasarkan laporan dari para perawi hadis (mubadditsîn), 'Â'isyah, Umm al-Mu'minîn, dinikahi oleh Nabi saw. di usia 6 tahun, dan mulai hidup serumah dengannya pada usia 9 tahun. Berikut, hadis-hadis yang diriwayatkan oleh al-Bukhârî dan Muslim terkait dengan informasi di atas:

"Khadijah wafat 3 tahun sebelum hijrah Nabi ke Madinah. Rasul saw. sempat menduda kurang lebih 2 tahun sampai kemudian menikahi 'Â'isyah yang kala itu ia berusia 6 tahun. Namun, Nabi saw. baru hidup serumah dengan 'Â'isyah saat gadis cilik itu telah memasuki usia 9 tahun." 7

"Nabi saw. menikahiku di Mekah saat berusia 6 tahun setelah kewafatan Khadijah. Namun beliau baru hidup serumah denganku di Madinah ketika aku telah berusia 9 tahun." 8

Selain dua hadis di atas, riwayat-riwayat hadis yang memberitakannya demikian melimpah (terdapat dalam al-Kutub al-Sittah dan kitab-kitab hadis lainnya) sehingga dapat dikatakan bahwa informasi perihal usia 'Aisyah ketika dinikahi oleh Nabi saw. itu telah mencapai level mutawâtir.

Tidak ada silang pendapat di kalangan para ulama dalam memahami bunyi literal dari teks-teks hadis di atas-di mana mereka menfatwakan kebolehan mengawini gadis ingusan tanpa ada ketentuan batasan usia minimal. Berikut, kutipan pernyataan dari para fuqaha' terkait persoalan ini, misalnya, Al-Sarkhasi (w. $490 \mathrm{H}$ ), salah seorang ulama terkemuka dalam mazhab Hanafi, menulis dalam bukunya, al-Mabsûth:

7Abû Abd al-Lâh Muhammad bin Ismâil bin Ibrâhim bin al-Mughîrah

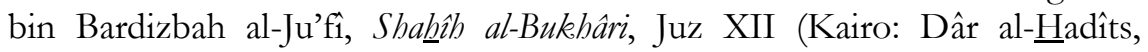
2004), 284.

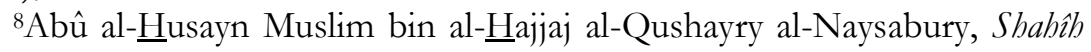
Muslim, Juz VII (Beirut: Dâr al-Fikr, t.t.), 244. 
"Kita mendengar bahwa Nabi saw. menikahi Â'isyah sewaktu masih kanak-kanak berusia 6 tahun. Beliau baru hidup serumah dengannya saat Â'isyah telah berusia 9 tahun. Kehidupan rumah tangga di antara keduanya hanya berlangsung selama 9 tahun ketika Nabi saw. berpulang ke hadirat Ilahi pada tahun $11 \mathrm{H}$. Hadis tentang usia 'Â'isyah saat dinikahi oleh Nabi saw. tersebut merupakan bukti perihal legalitas pernikahan anak-anak (di bawah umur)."9

Dari kalangan ulama mazhab Mâliki, Ibn 'Abd al-Barr mengemukakan:

"Abû Bakr al-Shiddîq menikahkan puterinya, 'Â'isyah yang masih berstatus gadis belia di usia 6 atau 7 tahun. Oleh karena itu, seorang ayah boleh mengawinkan puterinya yang masih kanak-kanak, baik perawan maupun janda, meski belum mencapai usia menstruasi, tanpa seijinnya" (Ibn "Abd al-Barr, 1407 H:231). Para ulama juga sepakat bahwa ayah berhak menikahkan anak gadisnya yang masih kanak-kanak tanpa meminta persetujuannya, dengan dasar perkawinan Nabi saw. dengan A'isyah yang kala itu masih berusia 6 tahun."10

Demikian pula al-Syâfîî, dalam pembahasan tentang "meminta izin gadis kecil untuk dinikahkan", menyatakan:

'Â'isyah dinikahkan oleh ayahnya, Abû Bakr dengan Nabi saw.. Hal itu menunjukkan bahwa Abû Bakr (sebagai orang tua) lebih berhak daripada 'A'isyah (sebagai anak) dalam persoalan perkawinannya. Sebab, bocah berusia 7 dan 9 tahun tentu belum memiliki kedewasaan yang memadai (untuk mengambil keputusan)."11

Sedangkan dari Mazhab Hanbali, Ibn Qudâmah menandaskan

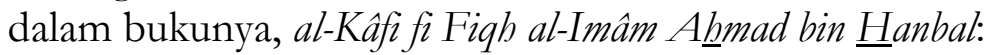

“Adapun gadis merdeka, maka ayahnya memegang otoritas pernikahan puterinya yang masih perawan (tanpa diperselisihkan oleh para ulama).

'Shams al-Din al-Sarkhasy, al-Mabsûth, Juz IV (Beirut: Dâr al-Ma'rifah, $1406 \mathrm{H}), 212$.

${ }^{10} \mathrm{Ibn}$ 'Abd al-Barr al-Namri, al-Kâfi (Beirut: Dâr al-Kutub al-'Ilmiyah, 1407 H), 231. Periksa juga Ibn 'Abd al-Barr al-Namri, al-Tambîd, Juz XIX (Maroko: Wizârat al-Awqâf wa al-Su'ûn al-Islâmiyyah, 1387 H), 98.

11Al-Syâfi'î, al-Umm, Juz V (Beirut: Dâr al-Ma'rifah, 1393 H), 167. 
Dasarnya, Abû Bakr al-Shiddiq mengawinkan puterinya 'Â'isyah dengan

Nabi saw. ketika masih berumur 6 tahun."12

Dalam konteks ini pula, al-Qarârî mengemukakan: "Redaksiredaksi kutipan di atas merupakan dalil yang paling fasih atas kebolehan menikahkan gadis kecil (al-Shaghîrah). Barangsiapa yang menggugatnya, berarti ia menentang ijmâ.".13

Perlu pula untuk digarisbawahi bahwa ulama fiqh klasik sama sekali tidak memberikan catatan definisi untuk sebutan "gadis kecil" (shaghirah) yang diperbolehkan untuk dinikahkan itu. Penulis tidak menemukan, misalnya, pendapat seorang faqîh yang membatasi sebutan shaghirah untuk anak yang telah berumur 6 tahun-dengan mengacu pada bunyi literal dari hadis-hadis tentang usia 'Â'isyah kala menikah. Dan, tidak seorang faqîh pun yang berfatwa bahwa tolok ukurnya adalah datangnya fase haid-dengan dasar bahwa Allah saw. menetapkan dalam salah satu ayat masa 'iddah (masa tunggu) bagi shaghîrah yang diceraikan itu adalah 3 bulan: "Perempuan-perempuan yang tidak haid lagi (monopouse) di antara perempuan-perempuanmu, jika kamu ragu-ragu (tentang masa iddahnya), maka iddah mereka adalah 3 bulan; dan begitu pula perempuan-perempuan yang tidak haid."14

Yang dimaksud dengan perempuan-perempuan yang belum haid dalam ayat di atas itu adalah shaghîrah (gadis-gadis kecil yang masih di bawah umur). Ayat di atas sekaligus menegaskan kebolehan shaghîrah yang belum mencapai usia haid untuk dinikahkan. Mengomentari ayat di atas itu pula, Abû Bakr alJashshâs menulis dalam Ablkâm al-Qur'ân-nya sebagai berikut, "Allah swt. menetapkan keabsahan perceraian gadis kecil yang belum mencapai usia haid-padahal talak tidak mungkin terjadi tanpa didahului oleh ikatan pernikahan resmi sebelumnya.

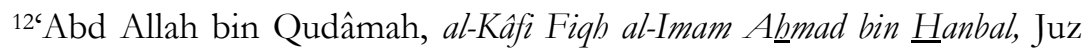
III (Beirut: al-Maktab al-Islâmi, 1408 H), 26.

${ }^{13} \mathrm{Al}$-Qarârî, "Tazuîj al-Banât li Tis' Sinîn bayn al-Nafy wa al-Itsbât", dalam www.ahlalhdeeth.com.

${ }^{14}$ Qs al-Thalâq [65]:4. 
Sehingga dapat disimpulkan bahwa ayat di atas melegalkan pernikahan anak yang masih di bawah umur."15

Pertanyaannya sekarang, jika tolok ukur kebolehan mengawinkan shaghîrah itu bukan "usia" dan bukan pula datangnya "haid", lantas apa parameter yang digunakan oleh para fuqaha' klasik? Mereka menyatakan bahwa tolok ukurnya ialah kesiapan si gadis untuk melakukan "aktivitas seksual" berikut segala konsekuensinya, seperti mengandung (hamil), melahirkan, dan menyusui. Atau dalam ungkapan yang lebih santun, meminjam istilah al-Qarârî:

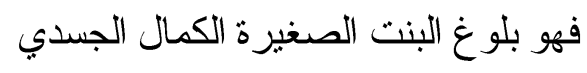

Artinya: "sampai si gadis kecil mencapai kesempurnaan dan kematangan fisik.."16

Hanya saja Ibn Syubramah (w. $144 \mathrm{H}$ ) memiliki pandangan lain-di mana ia melihat pernikahan Nabi saw. dengan 'Aisyah yang masih kanak-kanak itu merupakan khusûsiyyah-nya. ${ }^{17}$ Pendapat Ibn Syubramah ini banyak menuai kritik dari sejawatnya para fuqaha'. Dasarnya, tidak ada seorang pun dari kalangan sahabat maupun tabi'in yang menegaskan bahwa praktik pernikahan Nabi dengan 'Â'isyah itu merupakan khusûsiyyah. ${ }^{18}$ Lebih jauh, Ibn Syubramah (dan orang-orang sependapat dengannya) dituding telah membuka ruang bagi para pembenci Islam untuk mencela kepribadian Nabi saw. Misalnya, dengan menuding Nabi sebagai phedophil, yakni orang yang memiliki ketertarikan seksual terhadap anak di bawah umur.

Seperti diwartakan oleh banyak hadis, perkawinan Nabi dengan 'Â'isyah yang saat itu masih berusia 6 tahun (ada juga

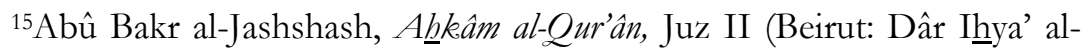
Turath al-'Arabi, $1405 \mathrm{H}), 346$.

${ }^{16} \mathrm{Al}$-Qarârî, "Tazwîj al-Banât li Tis' Sinîn bayn al-Nafy wa al-Itsbât", dalam www.ahlalhdeeth.com.

${ }^{17}$ Al-Shawkânî, Nayl al-Awthâr, Juz VI (Beirut: Dâr al-Jill, 1973), 252.

${ }^{18 I b n} \underline{H}$ azm al-Zhâhiri, al-Mạballa, Juz IX (Beirut: Dâr al-Awfaq alJadîdah, t.t.), 460 . 
yang meriwayatkan 7 tahun), pada hakekatnya hanyalah akad nikah saja. Pengasuhan 'Â'isyah, yang masih berstatus gadis ingusan (jâriyah) kala itu, tetap ditangani oleh kedua orang tuanya sampai ia mencapai pubertas di usia 9 tahun (pasca hijrah ke Madinah).

Tidak diragukan, praktik Nabi tersebut telah menjadi tradisi sosial dalam masyarakat Arab sebelumnya, yang diamini oleh utusan Allah itu. Seandainya hanya Nabi saw. seorang yang mempraktikkannya, tentu setidaknya kita akan mendengar riwayat yang memberitakan pertanyaan sahabat mengenai persoalan tersebut. ${ }^{19}$ Sejarah mencatat kasus pernikahan sejumlah sahabat dengan gadis di bawah umur, seperti yang dilakukan oleh 'Umar bin al-Khattâb ketika menikahi Ummu Kulthum (puteri 'Ali bin Abi Thâlib) dan Qudâmah bin Math'ghun yang menikahi puteri Zubayr bin 'Awwâm.

Begitulah, praktik tersebut merupakan tradisi hidup yang lazim terjadi dalam masyarakat Arab saat itu. Ketika seorang wanita telah siap secara seksual untuk bereproduksi (hamil, melahirkan, dan menyusui), maka ia akan dinikahkan di usia yang dini. Al-Bukhârî sendiri mendukung pendapat yang menyatakan bahwa tolok ukur dari kebolehan seorang gadis kecil (jâriyah) untuk dinikahkan adalah "kesiapan ragawi"-nya untuk berhubungan seksual yang ditandai dengan tibanya usia pubertas (bulûgh). ${ }^{20}$

Sandaran lain dari konklusi ini adalah kisah Umm Ruman (ibu 'Â'isyah) yang kerapkali memberikan kepada puterinya buah ketimun untuk mempercepat proses pematangan fisiknya (agar segera dapat hidup serumah dengan Nabi saw.), seperti diungkapkan sendiri oleh 'Â'isyah berikut ini:

${ }^{19}$ Lihat Ibn Qudâmah, al-Mughni II (Amman Yordania: Bayt al-Afkâr alDuwaliyyah, t.t.), 1600.

20Al-Shawkânî, Nayl..., 252. 
"Ibu selalu memperhatikan diriku karena ingin agar aku segera dewasa. Tujuannya, agar aku segera dapat hidup serumah dengan Nabi saw.. Untuk mewujudkannya, aku sering (diminta ibu) mengonsumsi kurma dan mentimun agar pertumbuhan fisikku menjadi lebih pesat."21

Mungkin muncul bantahan terhadap parameter kebolehan mengawinkan anak perempuan berdasarkan tercapainya usia pubertas (bulîgh) dengan menggunakan argumentasi hadis berikut: "Jika seorang bocah mencapai usia 9 tahun, maka ia telah menjadi seorang gadis dewasa (lady)." 22 Hadis tersebut secara eksplisit memang menyatakan bahwa periode transisi perkembangan individu dari kanak-kanak (jâriyah) ke dewasa (imra'ab) itu ditandai dengan tercapainya usia 9 tahun. Namun para fuqahâ' menolak hadis tersebut karena di dalam rantai sanad-nya terdapat perawi-perawi yang tidak dikenal (majhûl), seperti Abd al-Mâlik bin Mahran. ${ }^{23}$

Dengan berlandasan paparan berbagai mazhab tentang hukum perkawinan anak di bawah umur, maka banyak negara yang berpenduduk muslim yang memberlakukannya, walaupun dari segi akibat perkawinan dini bagi pelaku tidak dianalisis secara saksama dalam berbagai perspektif, seperti yang ditampilkan data-data negara yang mempraktikkan berikut.

\section{Perkawinan Anak Bawah Umur di Negara Berpenduduk Mayoritas Muslim}

Meskipun definisi pernikahan di bawah umur (child marriage/early marriage) juga diperuntukkan untuk anak lelaki (boys), namun, mayoritas anak yang menikah di bawah usia 18

${ }^{21}$ Abû Bakr Aḥmad bin Husayn bin Âli bin 'Abd al-Lâh al-Bayhaqi, Sunan al-Baihaqî al-Kubra, Juz VII (Mekah: Maktabah Dâr al-Baz, t.t.), 254, Hadis Nomer 14246 dan 14247.

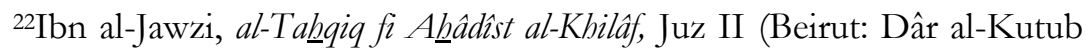
al-'Ilmiyah, $1415 \mathrm{H}), 267$.

${ }^{23} \mathrm{Al}-$ 'Uqaili, al-Dhufâ' al-'Uqaili, Juz III (Beirut: Dâr al-Kutub al'Ilmiyah, t.t.), 989. 
tahun adalah perempuan (girls). Juga, walaupun praktik pernikahan di bawah umur secara global menurun drastis dalam kurun waktu 30 tahun terakhir, namun kasus-kasusnya masih marak terjadi dalam kelompok masyarakat miskin, baik di negara-negara terbelakang maupun berkembang; di Asia Selatan, sekitar 48\% (kurang lebih 10 juta) gadis dikawinkan sebelum mencapai usia 18 tahun. Di Afrika, diperoleh angka 42\%; sedangkan di Amerika Latin dan Karibia, gadis yang dinikahkan sebelum berusia 18 tahun mencapai $29 \% .{ }^{24}$

ICRW pada tahun 2007 merilis rangking negara-negara dengan praktik child marriage tertinggi di seluruh dunia dengan judul sebagai berikut: Top 20 "Hot Spot" Countries for Child Marriage Ranking Country Percent Married Younger than 1:
1. Niger
76.6
2. Chad
71.5
3. Bangladesh
68.7
4. Mali
65.4
5. Guinea
64.5
6. Central African Republic
57.0
7. Nepal
56.1
8. Mozambique
9. Uganda
10. Burkina Faso
11. India
12. Ethiopia
13. Liberia
48.4
14. Yemen
48.4
15. Cameroon
16. Eritrea
47.0
17. Malawi
46.9

${ }^{24}$ UNICEF Website on Married Adolescents, Child Marriage Advocacy Programme: Fact Sheet on Child Marriage and Early Union (New York: UNFPA, 2004). 
18. Nicaragua

19. Nigeria

20. Zambia
43.3

43.3

42.1

Sumber: Demographic Health Survey (DHS) Data 25

Dari paparan data di atas dapat disimpulkan bahwa angka praktik pernikahan anak di bawah umur di negara-negara berpenduduk mayoritas muslim sangat tinggi. Memang banyak faktor yang mendorong terjadinya praktik child marriage atau early marriage, mulai dari yang berdimensi sosial, ekonomi hingga budaya. Namun, banyak spekulasi menyebutkan bahwa tingginya angka child marriage (early marriage) di negara-negara muslim tidak lepas dari faktor teologis-yakni justifikasi doktrin agama atas legalitas praktik tersebut. Dan, dalam konteks ini, pernikahan Nabi saw. dengan 'Aisyah yang masih "kanak-kanak" dijadikan sebagai model anutan oleh para pemeluk Islam.

\section{Resiko dan Bahaya dari Perkawinan Anak di Bawah Umur}

Mayoritas negara telah mendeklarasikan bahwa usia perkawinan minimal yang dilegalkan (the minimun legal age of marriage) adalah 18 tahun. ${ }^{26}$ Kebijakan tersebut merupakan implementasi dari Konvensi Hak Anak yang telah ditetapkan lewat forum Majelis Umum PBB tahun 1989. Meski demikian, diperkirakan lebih dari 100 juta anak akan menikah di bawah

25Jain, Saranga \& Kurz, Kathlee, "New Insights on Preventing Child Marriage: A Global Analysis on Factors and Programs", artikel International Center for Research on Women (ICRW) untuk The United States Agency for International Development. April 2007.

${ }^{26}$ Kebijakan tersebut merupakan implementasi dari Konvensi Hak Anak yang telah ditetapkan lewat forum Majelis Umum PBB tahun 1989. Selengkapnya baca Majelis Umum PBB, "Konvensi Hak Anak", diterjemahkan ke Bahasa Indonesia oleh Susi Septaviana dalam http://www.idp-europe.org/Indonesia / docs / Konvensi HakAnak.pdf (20 November 1989). 
umur dalam satu dekade mendatang. ${ }^{27}$ Padahal perkawinan di usia dini (early marriage) mendatangkan banyak resiko dan bahaya, seperti kematian di usia muda (dalam proses persalinan), terjangkit problem kesehatan, hidup dalam lingkaran kemiskinan, dan menderita buta aksara (karena tidak mengenyam pendidikan dasar).

\section{Kehamilan Prematur (Premature Pregnancy)}

Anak-anak, secara definitif, belum dewasa baik fisik maupun emosinya. Karena itu, ibu kecil beresiko melahirkan bayi prematur dengan berat badan di bawah rata-rata. Hal ini sangat berbahaya bagi bayi tersebut karena meningkatnya resiko kerusakan otak dan mental. Bayi yang lahir dengan berat kurang dari normal mempunyai resiko kematian 20 kali lebih besar pada tahun pertamanya dibanding bayi normal.

\section{Kematian Ibu (Maternal Mortality)}

Ibu kecil berusia antara 10-14 tahun beresiko meninggal dalam proses persalinan 5 kali lebih besar dari wanita dewasa. Persalinan yang berujung pada kematian merupakan faktor paling dominan dalam kematian gadis antara 15-19 tahun di seantero dunia. ${ }^{28}$ Di Kamerun, Ethiopia, dan Nigeria, kematian ibu muda berusia di bawah 16 tahun itu 6 kali lebih tinggi dari kematian ibu dewasa berusia antara 20-24 tahun. ${ }^{29}$

27J. Bruce \& S. Clark, "The Implications of Early Marriage for HIV/AIDS Policy", brief based on background paper prepared for the WHO/UNFPA/ Population Council Technical Consultation on Married Adolescents (New York: Population Council, 2004).

${ }^{28}$ United Nations, "We the Children: End-Decade", Review of the Follow-up to the World Summit for Children: Report of the SecretaryGeneral (A/S-27/3) (New York: United Nations, 2001).

${ }^{29}$ UNICEF Innocenti Research Centre, "Early Marriage: Child Spouses", No. 7.(Florence, Italy: UNICEF, 2001). Lacak melalui www.unicef-icdc.org/ publications/pdf/digest7e.pdf. 


\section{Tidak Berpendidikan (No Education)}

Hampir bisa dipastikan, pengantin kanak-kanak itu adalah generasi putus sekolah. Kesempatan mereka untuk mengenyam level pendidikan yang lebih tinggi menjadi terkebiri bahkan tidak sedikit pula yang tidak menyelesaikan bangku pendidikan dasar (primary education). Akibatnya, banyak di antara mereka yang buta aksara (illiterate). ${ }^{30}$ Sejumlah riset menyimpulkan, ada korelasi erat antara level pendidikan anak gadis dengan usianya saat pertama kali menikah. Semakin tinggi tingkat pendidikan yang ditempuhnya, semakin lambat pula ia menapaki jenjang pernikahan sehingga dapat dikatakan bahwa memasukkan dan menahan anak gadis di bangku sekolah merupakan cara terbaik untuk mencegahnya menikah dini. Berikut, statistik anak antara usia 15-19 tahun di sejumlah negara yang mengenyam pendidikan dasar maupun yang tidak.

\section{Problem Kesehatan (Health Problems)}

Kerusakan Tulang Panggul. Karena pertumbuhan tulang ibu kecil belum lagi lengkap, resiko kerusakan cepalopelvic (tulang panggul)-nya sangat tinggi. Pasalnya, bayi yang dilahirkan jauh lebih besar dari kemampuan tulang panggulnya. Ini berakibat pada sulit dan lamanya kelahiran dan mengancam rusaknya organ bayi jika dipaksakan. Kemungkinan, karena nutrisi yang kurang, ibu-ibu muda sering keguguran dan dapat terkena preeclampsia dan penyakit-penyakit lainnya.

Preeclampsia dan bentuk akhirnya, eclampsia, adalah sebuah penyakit yang khusus bagi kehamilan. Preeclampsia dicirikan dengan bertambahnya tekanan darah dan hilangnya protein dalam urine (proteinuria). Preeclampsia yang memburuk akan berkembang menjadi eclampsia, yang menambah seranganserangan penyakit lain dengan sympton yang lebih kompleks.

${ }^{30}$ Baca UNFPA, "Afghan Teens Speak Out Against Early Marriage World Population Day: A Personal Story" dalam http: / / www.unfpa.org/news / news.cfm?ID=346\&Language=1 (11 Juli 2003). 
Hubungan Seksual yang Tidak Aman. Dikarenakan mayoritas pengantin kanak-kanak harus berhenti sekolah lebih awal, mereka pun tidak familiar dengan isu-isu dan layanan-layanan kesehatan reproduksi yang bersifat dasar (basic reproductive health issues and services), termasuk resiko tertular HIV. Isolasi dan ketidakberdayaan juga turut menambah resiko kesehatan reproduksi mereka—di mana ibu kecil hanya memiliki otonomi diri dan kebebasan bergerak yang sangat terbatas. Tidak jarang, problemnya adalah ketiadaan izin dari pasangannya yang berpikiran sangat tradisional dan konservatif. Lebih memprihatinkan lagi, dalam beberapa kelompok masyarakat, pengantin kanak-kanak "diharapkan" segera memiliki momongan (infant) oleh lingkungannya. ${ }^{31}$

Selain persoalan seputar wawasan kesehatan reproduksi yang rendah, pengantin kanak-kanak juga dihadapkan pada problem hubungan seksual (sex intercourse) yang mengerikan. Menstruasi lazimnya terjadi pada usia sekitar 12 tahun. Resiko kontak seksual sebelum menstruasi, misalnya saja di usia 9 atau 11 tahun, muncul sebagai akibat dari rendahnya kadar hormon estrogen. Resiko yang biasanya muncul adalah trauma vagina seiring dengan robeknya tisu-tisu di dalamnya. Pasalnya, bagian vulva dan vaginal akan dipaksa melebar tanpa bisa kembali normal seperti pada wanita dewasa. Infeksi pasti akan muncul karena lemahnya jaringan tisu yang belum diperkuat oleh hormon estrogen ini. Kanker Cervic (Leher Rahim) merupakan ancaman terbesar dalam hal ini. Semakin muda si bocah menikah, maka semakin besar pula resikonya.

\section{Kekerasan Rumah Tangga (Abuse and Violence)}

Gadis-gadis kecil yang dikawinkan di usia dini lazimnya bersuamikan pria yang jauh lebih tua dari dirinya. Akibat margin usia yang sangat lebar inilah hampir selalu muncul problem

${ }^{31}$ UNFPA, "Child Marriage Fact Sheet" dalam http: //www.unfpa.org / news / news.cfm?ID=346\& Language=1 (2005). 
komunikasi keluarga maupun seksual antara kedua belah pihak. Riset di 16 negara sub Sahara Afrika memperoleh data bahwa selisih usia pengantin perempuan yang masih kanak-kanak dengan pasangannya itu rata-rata terpaut minimal 10 tahun lebih tua.

Model pernikahan dengan selisih usia terpaut jauh itu pada gilirannya sering menghadirkan "mimpi buruk" bagi pengantin perempuan-di mana mereka mengalami kekerasan (abuse and violence) dalam kehidupan rumah tangganya. Ironisnya, tindak kekerasan suami itu seringkali dijustifikasi secara normatif oleh tradisi (baca: agama). ${ }^{32}$ India merupakan negara dengan kekerasan domestik (baca: KDRT) tertinggi terhadap perempuan yang menikah di usia kisaran 18 tahun.

\section{Trauma Psikologis}

Gadis kecil yang melahirkan bayi merupakan suatu hal yang telah lama dielakkan oleh dunia kedokteran. Situasi ini sangat traumatik bagi sang ibu muda karena mencabut masa kanakkanaknya. Sebelum ia belajar mengenai hidup dan bereaksi secara tepat terhadap dirinya sendiri, ia harus mengasuh dan membesarkan bayi. Pendeknya, ia disegerakan untuk menjadi dewasa secara tidak wajar. Rasa marah dan penolakan adalah sikap yang umum terjadi dan lazimnya berlangsung dalam jangka waktu yang lama (bahkan tidak tertutup kemungkinan seumur hidup). Inilah yang kemudian memuncul trauma psikologis yang berkepanjangan.

\section{Tantangan Legislasi dan Harmonisasi Hukum Islam}

Seperti dikemukakan di awal tulisan ini, masalah perkawinan anak di bawah umur di Indonesia mendadak menghangat akhirakhir ini, khususnya setelah heboh pernikahan Pujiono Cahyo

${ }^{32} \mathrm{R}$. Jenson \& R. Thornton, "Early Female Marriage in the Developing World", dalam Gender and Development, vol. 11, no. 2, 9-19 (New York: Gender and Development, 2003). 
Widianto alias Syeikh Puji dengan Lutviana Ulfa, seorang gadis yang ditengarai masih berusia di bawah umur (12 tahun dan versi lain 15 tahun). Padahal kasus pernikahan di bawah umur bukanlah persoalan baru di Indonesia. Praktik ini sudah berlangsung lama dengan begitu banyak pelaku—tidak hanya di kota besar, namun juga di pedalaman. Penyebabnya pun bervariasi, mulai dari faktor ekonomi, rendahnya pendidikan, dangkalnya pemahaman budaya dan nilai-nilai agama tertentu hingga hamil terlebih dahulu (yang populer dengan istilah married by accident), dan lain-lain.

Selain menimbulkan masalah sosial, psikologis, dan kesehatan, perkawinan di bawah umur juga menimbulkan persoalan hukum. Pernikahan Syekh Puji dan Ulfa, misalnya, membuka ruang kontroversi antara Hukum Adat, Hukum Islam, serta Hukum Nasional dan Hukum Internasional, karena masing-masing memiliki sudut pandang yuridis yang berbeda. Kenyataan ini melahirkan, minimal, dua masalah hukum. Pertama, harmoninasi hukum antar sistem hukum yang satu dengan sistem hukum yang lain. Kedua, tantangan atas legislasi hukum perkawinan di Indonesia terkait dengan perkawinan di bawah umur.

Pasal 7 UU No. 1 Tahun 1974 tentang Perkawinan menyebutkan bahwa: "perkawinan banya diizinkan jika pibak pria sudah mencapai umur 19 tahun dan pihak wanita sudah mencapai umur 16 tahun". Namun, penyimpangan terhadap batas usia tersebut dapat terjadi ketika ada dispensasi yang diberikan oleh pengadilan ataupun pejabat lain yang ditunjuk oleh kedua orang tua dari pihak pria maupun pihak wanita (vide pasal 7 ayat 2). Undang-undang yang sama menyebutkan bahwa perkawinan harus didasarkan atas persetujuan kedua calon mempelai dan izin dari orang tua diharuskan bagi mempelai yang belum berusia 21 tahun.

Kompilasi Hukum Islam (KHI), yang disebarluaskan melalui Inpres No. 1 Tahun 1991, memuat perihal yang kurang lebih 
sama. Pada pasal 15, KHI menyebutkan bahwa batas usia perkawinan sama seperti pasal 7 UU No. 1 Tahun 1974, namun dengan tambahan alasan "untuk kemaslahatan keluarga dan rumah tangga." Maka, secara eksplisit tidak tercantum jelas larangan untuk menikah di bawah umur. Penyimpangan terhadapnya dapat dimungkinkan dengan adanya izin dari pengadilan atau pejabat yang berkompeten.

Hukum Islam, dalam hal ini al-Qur`an dan hadis, tidak menyebutkan secara spesifik tentang usia minimum untuk menikah. Persyaratan umum yang lazim dikenal adalah sudah baligh, berakal sehat, mampu membedakan yang baik dengan yang buruk sehingga dapat memberikan persetujuannya untuk menikah. Pasal 16 KHI menyebutkan bahwa perkawinan didasarkan atas persetujuan calon mempelai. Bentuk persetujuan calon mempelai wanita, dapat berupa pernyataan tegas dan nyata dengan tulisan, lisan, atau isyarat, tetapi dapat juga berupa diam dalam arti selama tidak ada penolakan yang tegas.

Begitu pula halnya dengan hukum adat. Hukum adat Indonesia, yang berbeda antara satu wilayah dengan wilayah lain, adalah hukum kebiasaan tidak tertulis yang tidak mengenal pembakuan umur seseorang dianggap layak untuk menikah. Biasanya seorang anak dinikahkan ketika ia dianggap telah mencapai fase atau peristiwa tertentu dalam kehidupannya. Dan, ini seringkali tidak terkait dengan umur tertentu.

Instrumen Hak Asasi Manusia-apakah yang bersifat internasional (International Human Rights Law) ataupun yang sudah diratifikasi oleh Pemerintah RI-tidak menyebutkan secara eksplisit tentang batas usia perkawinan. Konvensi Hak Anak (Convention on the Rights of the Child 1990 yang telah diratifikasi melalui Keppres No. 36 Tahun 1990) tidak menyebutkan usia minimal pernikahan selain menyebutkan bahwa yang disebut anak adalah mereka yang berusia di bawah 18 tahun. Juga, setiap negara peserta konvensi diwajibkan melindungi dan menghadirkan legislasi yang ramah anak, 
melindungi anak dan dalam kerangka kepentingan terbaik bagi anak (the best interest of the child).

Konvensi tentang "Kesepakatan untuk Menikah, Umur Minimum Menikah dan Pencatatan Pernikahan" (Convention on Consent to Marriage, Minimum Age for Marriage and Registration of Marriages) 1964 menyebutkan bahwa negara peserta konvensi ini akan mengupayakan lahirnya legislasi untuk mengatur permasalahan umur minimum untuk menikah dan bahwasanya pernikahan yang dilakukan di luar umur minimum yang ditetapkan adalah tidak berkekuatan hukum, terkecuali otoritas yang berwenang menetapkan dispensasi tertentu dengan alasan yang wajar dengan mengedepankan kepentingan pasangan yang akan menikah.

Indonesia belum menjadi negara pihak dari Konvensi 1964 tersebut, namun telah menetapkan usia minimum pernikahan melalui UU No. 1 Tahun 1974 tentang Perkawinan, alias sepuluh tahun setelah Konvensi tersebut lahir. UU No. 23 Tahun 2002 tentang Perlindungan Anak-sebagai instrumen HAM-juga tidak menyebutkan secara eksplisit tentang usia minimum menikah selain menegaskan bahwa anak adalah mereka yang berusia di bawah 18 tahun. Disebutkan pula, penyelenggaraan perlindungan anak berasaskan Pancasila dan UUD 1945 serta prinsip-prinsip dasar Konvensi Hak-hak Anak meliputi: non diskriminasi; kepentingan yang terbaik bagi anak; hak untuk hidup, kelangsungan hidup, dan perkembangan; dan penghargaan terhadap pendapat anak.

Merujuk pada hukum perkawinan Islam Indonesia, sudah nyata bahwa perkawinan di Indonesia harus memenuhi ketentuan batas usia minimum, yaitu 19 tahun bagi pria dan 16 tahun bagi wanita. Kendati demikian, pelanggaran terhadapnya tidak serta-merta dapat ditindak. Begitu banyak terjadi perkawinan di bawah umur, dan tak pernah ataupun minim terdengar ada kriminalisasi terhadap perbuatan tersebut, kendati pasal 288 KUHP telah menyebutkan bahwa barangsiapa dalam 
perkawinan bersetubuh dengan seorang wanita yang diketahuinya atau sepatutnya harus diduganya bahwa yang bersangkutan belum waktunya untuk dikawin, apabila mengakibatkan luka-luka diancam dengan pidana penjara paling lama 4 tahun. Jika mengakibatkan luka-luka berat diancam pidana penjara paling lama 8 tahun, dan jika mengakibatkan mati diancam pidana penjara paling lama 12 tahun.

Pernikahan Syekh Puji dengan Ulfa seperti menampar wajah pembuat hukum dan aparat hukum negeri ini. Karena kasus ini sebenarnya bukan yang pertama dan bukan pula yang terakhir. Kasus ini hanyalah satu kasus yang mengemuka dari ribuan kasus lainnya yang mengendap dan membeku di bawah permukaan laksana gunung es. Praktik nikah di bawah umur juga mengisyaratkan bahwa hukum perkawinan Indonesia nyaris seperti hukum yang "tidak bergigi”, karena begitu banyak terjadi pelanggaran terhadapnya tanpa dapat ditegakkan secara hukum.

Memang, urusan perkawinan adalah urusan keperdataan dan atau urusan pribadi warga negara. Hal mana membuat banyak pihak mempertanyakan, kenapa masalah perkawinan harus diatur oleh negara, bukankah perkawinan berada dalam ranah privat? Mengapa pernikahan Syekh Puji dan Ulfa harus dipersoalkan, bukankah kedua mempelai dan keluarganya tak keberatan?

Urusan perkawinan memang berada dalam wilayah keperdataan. Namun peristiwa tersebut adalah peristiwa hukum yang jelas menimbulkan sebab akibat dan hak-hak kewajiban para pihak. Maka, pengaturan dari negara tetap perlu. UndangUndang No. 1 Tahun 1974 sudah mencoba mengatur dengan mengunifikasi hukum perkawinan. Hukum agama dan hukum adat diakomodasi dalam UU tersebut, di samping hukum perdata Barat. Sungguh ini bukan perkara yang mudah, karena selamanya unifikasi di wilayah hukum pribadi dan hukum keluarga adalah sesuatu yang sulit. Indonesia adalah negara yang kaya dengan pluralitas hukum dan pluralitas sosial budaya. 
Apabila perkawinan tidak diatur oleh negara, maka akan berpotensi lahirnya ketidakadilan bagi pihak-pihak tertentu, utamanya bagi perempuan dan anak-anak yang dilahirkan. Dan, akhirnya akan merembet pada keluarga luas, lingkungan, masyarakat, hingga akhirnya menjadi problem negara juga. Undang-Undang Penghapusan Kekerasan dalam Rumah Tangga No. 23 tahun 2004 lahir antara lain karena maraknya fenomena kekerasan dalam perkawinan.

Namun, apabila negara mengatur terlalu banyak, dapat juga berpotensi pemaksaan hukum dan sentralisasi hukum negara. Perlu ditetapkan melalui peraturan perundang-undangan, mana masalah perkawinanan yang perlu diatur hukum negara dan mana yang tidak agar tidak mencederai hak-hak sipil warga negara. Inilah tantangan untuk hukum perkawinan kontemporer. Mampukah pembuat hukum dan aparat hukum mengkritisi dan melahirkan legislasi di wilayah hukum perkawinan yang menjamin perlindungan hukum bagi semua pihak dan pada saat bersamaan tetap melahirkan keadilan? Kemudian, mampukah pembuat hukum dan aparat hukum mengharmonisasi perbedaan klausul di berbagai sistem hukum perkawinan terkait dengan masalah-masalah perkawinan kontemporer?

Merevisi UU No. 1 Tahun 1974 adalah satu alternatif dan tidaklah terlalu ambisius. ${ }^{33}$ Namun demikian, perlu dipikirkan harmonisasi dan lahirnya legislasi yang dapat mengakomodasi semua sistem hukum yang hidup tanpa harus mencederai hakhak sipil masyarakat dalam wilayah hukum perkawinan.

\section{Catatan Akhir}

Untuk mereduksi praktik pernikahan anak di bawah umur, menurut penulis, ada beberapa hal yang dapat dilakukan.

${ }^{33}$ Baca Ratna Batara Munti, "Pokok-Pokok Pikiran Usulan Amandemen UU Perkawinan" dalam situs LBH APIK - http://www.lbh-apik.or.id (Tahun 2006). 
Pertama, gadis dengan pendidikan yang cukup (apalagi tinggi) memiliki probabilitas 6 kali lebih kecil untuk menikah dini dibanding gadis-gadis yang hanya mengenyam pendidikan rendah, terlebih lagi tanpa pendidikan di bangku sekolah sama sekali. Itu artinya, pendidikan dapat berperan menunda waktu pernikahan sampai pada usia yang cukup. Selain itu melalui pendidikan, gadis-gadis muda dapat memperoleh alternatif kesempatan sekaligus mengembangkan potensi dirinya. Dan, pada gilirannya, diharapkan dapat mengangkat status sosialekonominya ke level yang lebih baik.

Kedua, negara-negara miskin di dunia, berdasarkan sejumlah riset, memiliki tingkat praktik pernikahan di bawah umur yang sangat tinggi. Keluarga-keluarga di sana menikahkan anaknya sedini mungkin agar dapat segera bebas dari beban pembiayaan atas diri anak-anak gadisnya. Hal itu dilakukan dengan diiringi harapan agar anak-anaknya segera mengalami perbaikan ekonomi pasca pernikahan. Meski pada kenyataannya, mereka tetap berada dalam lingkaran kemiskinan (the circle of poverty) bahkan lebih buruk dan tragis lagi. Praktik child marriage di mayoritas negara di sub Sahara Afrika, Asia Selatan, Timur Tengah, dan Afrika Utara terekam sangat tinggi-di mana gadisgadis muda dikawinkan tidak lama setelah mereka mencapai pubertas bahkan ada pula yang dinikahkan sebelum itu. ${ }^{34}$

Jika salah satu penyebab tingginya praktik child marriageseperti dikemukakan di atas-adalah faktor kemiskinan, maka solusi pencegahan dan pemecahan tentunya adalah dengan mendorong akselerasi perbaikan ekonomi dan kesejahteraan lewat penyediaan lapangan pekerjaan yang layak dan memadai. ${ }^{35}$

${ }^{34} \mathrm{UNICEF}$ website on Married Adolescents, Child Marriage Advocacy Programme: Fact Sheet on Child Marriage and Early Union (New York: UNFPA, 2004).

${ }^{35}$ The Population Council, "Adolescent and Youth Sexual and Reproductive Health: Charting Directions for a Second Generation of Programming", A Report on a Workshop of the UNFPA in Collaboration 
Bukti konkretnya adalah negara-negara yang sering disebut sebagai The East Asian Miracles (Taiwan, Korea Selatan, dan Thailand)_di mana negara-negara tersebut secara umum sukses meminimalisir praktik pernikahan di bawah umur berkat pertumbuhan ekonominya yang tinggi.

\section{Daftar Pustaka}

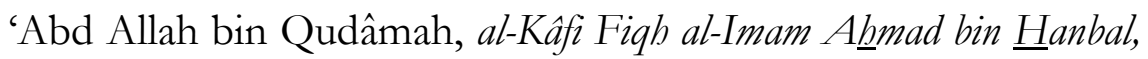
Juz III (Beirut: al-Maktab al-Islâmi, 1408 H), 26.

Abû Abd al-Lâh Muhammad bin Ismâil bin Ibrâhim bin alMughîrah bin Bardizbah al-Ju'fî, Shahîh al-Bukhâri, Juz XII (Kairo: Dâr al-Hadîts, 2004), 284.

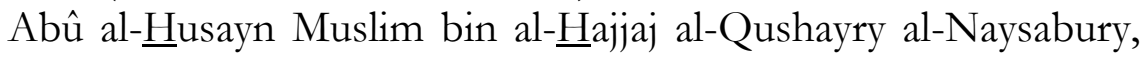
Shahîh Muslim, Juz VII (Beirut: Dâr al-Fikr, t.t.), 244.

Abû Bakr Ahmad bin Husayn bin Âli bin 'Abd al-Lâh alBayhaqi, Sunan al-Baihaqî al-Kubra, Juz VII (Mekah: Maktabah Dâr al-Baz, t.t.), 254, Hadis Nomer 14246 dan 14247.

Abû Bakr al-Jashshash, A $\underline{h} \hat{a}$ am al-Qur'ân, Juz II (Beirut: Dâr Ihya' al-Turath al-'Arabi, 1405 H), 346.

Al-'Uqaili, al-Dhu'fâ' al-'Uqaili, Juz III (Beirut: Dâr al-Kutub al'Ilmiyah, t.t.), 989.

Al-Qarârî, "Tažnij al-Banât li Tis' Sinîn bayn al-Nafy wa al-Itsbât", dalam www.ahlalhdeeth.com.

Al-Shawkânî, Nayl al-Awthâr, Juz VI (Beirut: Dâr al-Jill, 1973), 252.

Al-Syâfi'î, al-Umm, Juz V (Beirut: Dâr al-Ma'rifah, 1393 H), 167.

Chazizah Gusnita, "Syekh Puji: Saya Punya Dasar Agama, Nggak Ngawur", dalam http://wnw. detiknews.com / read/

with the Population Council, 1-3 May 2002 (New York: The Population Council, 2002). 
2008/10/23/ 150516/ 1024883/ 10/ syekh-puji-saya-punyadasar-agama-nggak-ngawur; diakses 23 Oktober 2008.

Febrianti Abbasuni, "Negara Tidak Boleh Membatasi Usia Pernikahan!", ～bttp:// bizbut-tabrir.or.id/2008/11/21/ bolebkah-negara-membatasi-usia-minimal-pernikahan/; diakses 21 November 2008.

Ibn 'Abd al-Barr al-Namri, al-Kâfi (Beirut: Dâr al-Kutub al'Ilmiyah, $1407 \mathrm{H}), 231$. Periksa juga Ibn 'Abd al-Barr alNamri, al-Tambîd, Juz XIX (Maroko: Wizârat al-Awqâf wa al-Su'ûn al-Islâmiyyah, 1387 H), 98.

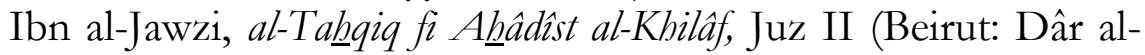
Kutub al-'Ilmiyah, 1415 H), 267.

Ibn ㅂazm al-Zhâhiri, al-Mạhalla, Juz IX (Beirut: Dâr al-Awfaq al-Jadîdah, t.t.), 460.

Ibn Qudâmah, al-Mughni II (Amman Yordania: Bayt al-Afkâr alDuwaliyyah, t.t.), 1600.

Iin Yumiyanti, "MUI: Tak Masalah Syekh Puji Dipidanakan", bttp:/ / www.detiknews.com/ read/ 2008/10/22/165612/ 1024278/10/mui-tak-masalah-syek-h-puji-dipidanakan; diakses tanggal 22 Oktober 2008.

J. Bruce \& S. Clark, "The Implications of Early Marriage for HIV/AIDS Policy", brief based on background paper prepared for the WHO/UNFPA/ Population Council Technical Consultation on Married Adolescents (New York: Population Council, 2004).

Majelis Umum PBB, "Konvensi Hak Anak", diterjemahkan ke Bahasa Indonesia oleh Susi Septaviana, bttp://www.idpeurope.org/Indonesia / docs / Konvensi Hak.Anak.pdf; diakses tanggal 20 November 1989.

R. Jenson \& R. Thornton, "Early Female Marriage in the Developing World", dalam Gender and Development, vol. 11, no. 2, 9-19 (New York: Gender and Development, 2003).

Ratna Batara Munti, "Pokok-Pokok Pikiran Usulan Amandemen

UU Perkawinan", bttp:/ / www.lbh-apik.or.id 
Saranga Jain \& Kathlee Kurz, "New Insights on Preventing Child Marriage: A Global Analysis on Factors and Programs", artikel International Center for Research on Women (ICRW) untuk The United States Agency for International Development. April 2007.

Shams al-Din al-Sarkhasy, al-Mabsûth, Juz IV (Beirut: Dâr alMa'rifah, $1406 \mathrm{H}), 212$.

Suara Media, "Syekh Puji Menikahi Bocah Berusia 12 Tahun", 26 Oktober 2008, 1.

Sulayman al-Qarari, "Tazwì al-Banât Li Tis' Sinîn bayn al-Nafy Wa al-Itsbât", www.ablalbdeeth.com/vb/ attachment.php?attachmentid $=60364 \% d=1224443807$.

The Population Council. "Adolescent and Youth Sexual and Reproductive Health: Charting Directions for a Second Generation of Programming." A Report on a Workshop of the UNFPA in Collaboration with the Population Council, 1-3 May 2002. New York: The Population Council, 2002.

Undang Undang Nomor 1 Tahun 1974 tentang Perkawinan. Undang Undang Nomor 23 Tahun 2002 tentang Perlindungan Anak.

UNFPA, "Afghan Teens Speak Out Against Early Marriage World Population Day: A Personal Story", bttp: / / www.unfpa.org $/$ news $\quad /$ news.cfm? ID $=346 \&$ Language $=1$; diakses tanggal 11 Juli 2003. , "Child Marriage Fact Sheet", bttp: / / wmw.unfpa.org / news / news.cfm?ID=346 \& Language $=1$

UNICEF Innocenti Research Centre, "Early Marriage: Child Spouses", No. 7.(Florence, Italy: UNICEF, 2001), www.uniceficdc.org/ publications/pdf/digest7e.pdf.

UNICEF website on Married Adolescents, Child Marriage Advocacy Programme: Fact Sheet on Child Marriage and Early Union (New York: UNFPA, 2004). 
UNICEF website on Married Adolescents, Child Marriage Advocacy Programme: Fact Sheet on Child Marriage and Early Union (New York: UNFPA, 2004).

UNICEF, Early Marriage: A Harmful Traditional Practice (New York: United Nations, 2005).

United Nations, "We the Children: End-Decade", Review of the Follow-up to the World Summit for Children: Report of the Secretary-General (A/S-27/3) (New York: United Nations, 2001).

Yusuf Hanafi, "Benarkah Nabi Menikahi Gadis di Bawah Umur?”, http://wmw.islamlib.com; diakses tanggal 11 November 2008. Artikel tersebut merupakan saduran dari tulisan T.O. Shavanas, "Was Ayesha A Six-Year-Old Bridge", bttp:// www.iine.net/node/58. 